\title{
The Relationship Between the Level of Physical Activity and Dementia in Elderly Residents of Nursing Homes in Tehran
}

\author{
Mehdi Kushkestani*, Shiva ENosrani, Mohsen Parvani and Sohrab Rezaei \\ M.Sc. Student of Exercise Physiology, Faculty of Physical Education and Sport Sciences, AllamehTabatabai University, Iran
}

*Corresponding author: Mehdi Kushkestani, Faculty of Physical Education and Sport Sciences, AllamehTabatabai University, Iran

\section{ARTICLE INFO}

Received: 慧 August 04, 2020

Published: 蔧 August 10, 2020

Citation: Mehdi Kushkestani, Shiva ENosrani, Mohsen Parvani and Sohrab Rezaei. The Relationship Between the Level of Physical Activity and Dementia in Elderly Residents of Nursing Homes in Tehran. Biomed J Sci \& Tech Res 29(3)-2020. BJSTR. MS.ID.004800.

Keywords: Aged; Exercise; Nursing Homes; Cognitive Dysfunction; Dementia

\author{
ABSTRACT
}

Background: Dementia is one of the common geriatric syndromes that increase disability and dependency among older people worldwide. Physical activity can be considered as a simple approach to delay its onset and control the development. This study was conducted to examine the association between the level of physical activity and risk of dementia among Iranian elderly people living in nursing homes in Tehran.

Methods: The present study was a cross-sectional with a descriptive correlational design. To collect data, anthropometrics, body composition indices and blood pressure of subjects were measured and recorded. Then, questionnaires were completed by interviewers to screen and assess dementia and the amount of physical activity. Data were analyzed using SPSS 21 software at a significant level of $\mathrm{P}<0.05$.

Results: Classification of subjects on the basis of Mini Mental State Examination (MMSE) score showed that $49.5 \%$ of subjects were dementia-free while $50.4 \%$ showed the sign of cognitive impairment. The comparison between the groups highlighted that physical activity and the level of education was lower in the elderly with dementia while the age was higher. Also, the results of Pearson correlation coefficient and hierarchical regression analysis showed there were positive and significant relationship between physical activity $(\mathrm{r}=0.36, \mathrm{P}<0.01)$ and education $(\mathrm{r}=0.61, \mathrm{p}<0.01)$ with dementia score in the elderly, while there was a negative correlation between age and dementia score $(\mathrm{p}<0.01)$. In addition, a negative significant relationship between age and the level of physical activity was detected ( $\mathrm{r}=-0.27, \mathrm{p}<0.01)$. After controlling the age and education factors, physical activity could able to explain $6.6 \%$ of cognitive changes $(\mathrm{P}<0.001)$. One-way Analysis of Covariance (ANCOVA) indicated that cognitive impairment was higher in the elderly with low physical activity $(\mathrm{P}<0.001)$.

Conclusion: Regular exercise and an active lifestyle were associated with a decreased risk of dementia. Therefore, managers of nursing homes should develop effective health and exercise programs as well as providing proper environments to persuade their residents toward an active lifestyle.

\section{Introduction}

The world's elderly population is being increased dramatically. According to the world health organization (WHO) report, by 2050, the number of people aged 60 years and older around the world will increase to a total 2 billion, from 900 million in 2015[1]. However, the significant portion of the increase in the elderly population will belong to developing countries such as Iran. According to the census records in Iran, about $9.27 \%$ of the total population was over 60 years in 2016[2]. Aging process refers to the physical, psychological, and social changes; in which older adults are more susceptible to age-related diseases, functional impairment, and physical inability. Of the common diseases, dementia increasingly affects older people[3]. It is reported that by 2030, the number of 
people living with dementia in Eastern Mediterranean countries increase to 4.4 million people[4]. In Iran, the prevalence of dementia for people aged over 60 years has been reported $7.9 \%$ while, it increases to $8.1 \%$.based on WHO age standards[5]. Meanwhile, physical inactivity which is considered as a fourth leading risk factor for mortality decreases with advancing age[6]

Increasing longevity and subsequently the worldwide growth of the aging population have raised concerns about the health of older people. Several studies show that the risk of many diseases such as osteoporosis, high blood pressure, diabetes and cardiovascular disease increase with age [3,7]. Meanwhile, dementia is one of the most prevalent geriatric syndromes that is aggravated by aging[8] Geriatric syndromes are complex clinical symptoms which have common risk factors and are not considered as specific and independent diseases of aging. Syndromes such as dementia, malnutrition, depression, fall, polypharmacy, urinary incontinence, sarcopenia, and weakness are the most important causes of death that increase health care costs[9]. The dementia syndrome which was the fifth cause of death in 2016[10], is linked to the development of other syndromes such as malnutrition, delusions and incontinence[9]. In fact, dementia is a general and comprehensive term for progressive neuro-cognitive impairment. The associated risk factors of this syndrome are divided into two groups: modifiable and unmodifiable. The unmodifiable factors are age, heredity and the Apo lipoprotein E gene while modifiable factors are obesity, smoking, and physical inactivity[11].

According to the World Health Organization, 47.5 million people worldwide have dementia, of whom 90-98\% are over 65 years [12]. Studies have shown that age is the most important risk factor for this disease. Accordingly, the prevalence of Alzheimer doubles every five years after the age of 65[13]. Internationally, the prevalence of dementia has been reported around $58 \%$ in elderly residents of nursing homes [14]. Similarly, the prevalence of dementia among elderly residents of nursing homes in Tehran province was reported at $43.4 \%[15]$.Researchers now have found that dementia syndrome, develops over decades the same as heart disease and cancer and is largely influenced by the individual's lifestyle. In fact, several studies have shown that risk factors such as cholesterol, high blood pressure, obesity, depression, nutrition, sleep, and physical inactivity significantly affect the disease [1617]. It has been well established that physical activity and diet play an effective role in preventing, controlling and treating chronic diseases such as hypertension, metabolic and cardiovascular disease, age-related dysfunction (geriatric syndrome) the same as Sarcopenia, severe fatigue, fall, and improved quality of life [18, 22]. A recent research has suggested that regular physical activity has a significant role in the prevention of dementia and cognitive impairment by reducing and controlling its risk factors such as diabetes, and hypertension [23]. Also, a study has demonstrated that low levels of physical activity increase the risk of dementia and cognitive impairment [24]. A cohort study with 1740 participants aged 65 years or older showed that regular exercise was associated with a delay in the onset of disease [25]. Despite the regular physical activity recommendations, research shows that residents of nursing home spend most of their time seated or lying down, even if they are capable to do their activities without any assistance [26]. Regarding the dementia prevalence and the lack of therapeutic approaches, it is essential to identify modifiable factors that change the course of the disease and provide safe and effective approaches to prevent and control it. Therefore, considering the benefits of exercise and physical activity in prevention, control and decreasing the development of dementia, we assumed that the higher level of physical activity in elderly people living in nursing homes was associated with a lower risk of dementia. Therefore, the purpose of this study was to investigate the relationship between dementia and physical activity in elderly residents of nursing homes in Tehran.

\section{Material and Method}

\section{Subjects}

This is a cross-sectional-correlational study with questionnaire design. The statistical society consists of all elderly people living in nursing homes in Tehran. The sample size included 121 individuals of the different urban districts of Tehran through cluster and random sampling methods. Sample size calculated by the Cochran formula. Eligible subjects were selected by assistance of nursing staff who knew the participants well. The inclusion criteria included: aged over 60 , more than 3 months of accommodation in nursing homes, to be able to interview. The exclusion criteria included: diagnosis of severe dementia and Alzheimer, BMI less than $15\left(\mathrm{~kg} / \mathrm{m}^{2}\right)$, residents with psychosis or having severe speech, hearing, or vision problems. Written informed consent was obtained prior to inclusion, then subjects were interviewed separately to collect the information.

\section{Anthropometric, Body Composition and Blood Pressure Assessment}

The subjects' weight and height were measured to $0.1 \mathrm{~kg}$ and $0.1 \mathrm{~cm}$ by OMRON digital scale and wall-sticker tape meter respectively with minimum clothing and no shoes. Body mass index was calculated as body weight in kg divided by squares of height in meters $\left(\mathrm{kg} / \mathrm{m}^{2}\right)$. The subjects' blood pressure was measured and recorded in the sitting position and after 5 minutes at rest, of the left arm placed at the level of the heart by Omron Digital Automatic Blood Pressure Monitor (M2, Omron).

\section{Dementia Assessment}

MMSE was used to screen and evaluate dementia and cognitive impairment. This test consists of items concerning orientation, word registration and recall, attention, naming, reading, writing, following commends and figure copying. A higher score indicates better performance and the maximum score is 30 . Scores of 22 or below are accepted as a sign of cognitive disorder for the Iranian population. The validity and reliability of the Persian version of the test have been confirmed [27] . 


\section{Physical Activity Assessment}

PASE was used to assess the level of physical activity among the elderly. The questionnaire consists of 10 questions with four answer choices, which evaluates the duration, frequency and intensity level of physical activity in three domains of occupational, household and leisure activities undertaken over a one-week period. The final score of the individual is calculated by scoring each activity. The validity and reliability of the questionnaire with Cronbach alpha $0.97 \%$ have been confirmed [28].

\section{Statistical Analyses}

Normality of distribution for continuous variables was tested by the Kolmogorov-Smirnov test. Normal distribution data were presented as mean $\pm S D$, and the differences among groups were compared by unpaired Student's t-test or analysis of variance. Also, Pearson correlation coefficient test was used for the correlation between variables at the significance level of $\mathrm{p}<0.05$. following controlling variables, hierarchical regression was used to determine the predictability of dementia regarding physical activity. Also, 1-way ANCOVA was used to determine the difference between dementia scores in three levels of physical activity. Prior to the ANCOVA test, the Levene's test for equality of variances was performed $(p>0.05)$. All statistical analyses were conducted with "SPSS 21".

\section{Results}

By applying the recommended cut-off point 22 on MMSE [27], participants were classified as dementia and dementia free subjects. The characteristics of older adults with and without dementia are summarized in Table 1. Compared with the non-dementia group, the dementia group had higher age, but lower PASE score and education $(\mathrm{p}<0.01)$. As presented in Table 2, physical activity and education have positive significant relationship with dementia $(r=0.36, r=0.61 \mathrm{p}<0.01)$. This illustrates that with an increase in the PASE score and the level of education, the MMSE score increases too. Also, there was a negative significant relationship between dementia and age $(r=-0.27, p<0.002)$. i.e. with an increase of age, MMSE scores decrease. Furthermore, a negative significant relationship between age and the level of physical activity was detected $(\mathrm{r}=-0.25, \mathrm{p}<0.004)$. Also, weight was significantly correlated with dementia $(r=0.30, \mathrm{P}<0.001)$. Moreover, a significant positive correlation was found between the level of education and physical activity $(\mathrm{r}=0.29, \mathrm{p}<0.001)$.

Table 1: Characteristics of subjects with and without dementia.

\begin{tabular}{|c|c|c|c|}
\hline Variables & $\begin{array}{c}\text { Non- } \\
\text { dementia(61) }\end{array}$ & dementia (60) & P value \\
\hline Age(years) & $71.48 \pm 8.42$ & $76 \pm 8.81$ & 0.005 \\
\hline Height(cm) & $157.03 \pm 10.23$ & $152.62 \pm 10.31$ & 0.020 \\
\hline Weight(kg) & $64.10 \pm 13.23$ & $60.28 \pm 13.16$ & 0.114 \\
\hline Education & & & 0.001 \\
\hline Not literate & $2(1.7 \%)$ & $26(21.5 \%)$ & \\
\hline High school & $14(11.6 \%)$ & $17(14.0 \%)$ & \\
\hline Diploma & $26(21.5 \%)$ & $16(13.2 \%)$ & \\
\hline Bachelor & $14(11.6 \%)$ & $1(0.8 \%)$ & \\
\hline Phd & $5(4.1 \%)$ & 0 & \\
\hline BMI (kg/m2) & $26.83 \pm 6.23$ & $26.86 \pm 6.57$ & 0.983 \\
\hline SBP (mmHg) & $135.93 \pm 27.21$ & $134.58 \pm 20.93$ & 0.760 \\
\hline DBP (mmHg) & $85.41 \pm 15.62$ & $80.18 \pm 13.75$ & 0.053 \\
\hline Heart rate & $77.02 \pm 14854$ & $78.40 \pm 18.93$ & 0.655 \\
\hline PASE & $54.13 \pm 54.74$ & $21.49 \pm 35.36$ & 0.001 \\
\hline
\end{tabular}

SBP:Systolic Blood Pressure; DBP:Diastolic Blood Pressure; PASE:Physical Activity For Elderly

Table 2: Correlation between age, education, weight, physical activity and dementia.

\begin{tabular}{|c|c|c|c|c|c|c|}
\hline & & Age & Education & Weight & Physical activity & Dementia \\
\hline \multirow{2}{*}{ Dementia } & Pearson correlation & -0.275 & 0.616 & 0.304 & 0.365 & \multirow{2}{*}{1} \\
\hline & $\operatorname{Sig}(2$-tailed $)$ & $0.002^{* *}$ & $0.001^{* *}$ & $0.001^{* *}$ & $0.001^{* *}$ & \\
\hline \multirow{2}{*}{ Physical activity } & Pearson correlation & -0.257 & 0.292 & 0.145 & \multirow[b]{2}{*}{1} & \\
\hline & $\operatorname{Sig}(2$-tailed) & $0.004^{* *}$ & $0.001^{* *}$ & 0.112 & & \\
\hline \multirow[b]{2}{*}{ Weight } & Pearson correlation & -0.216 & 0.101 & \multirow[b]{2}{*}{1} & & \\
\hline & $\operatorname{Sig}(2$-tailed $)$ & $0.017 *$ & 0.268 & & & \\
\hline \multirow[b]{2}{*}{ Education } & Pearson correlation & -0.227 & \multirow{2}{*}{1} & & & \\
\hline & $\operatorname{Sig}(2$-tailed $)$ & $0.012^{*}$ & & & & \\
\hline \multirow[b]{2}{*}{ Age } & Pearson correlation & \multirow{2}{*}{1} & & & & \\
\hline & $\operatorname{Sig}(2$-tailed) & & & & & \\
\hline
\end{tabular}

${ }^{*}$ p- value $<0.05,{ }^{* *}$ p-value $<0.01$ 
In this regard, age and education were considered as intervening variables in our study. In order to identify age and education effects on the MMSE score, hierarchical regression was used. Physical activity contributes to $6.6 \%$ of cognitive change (Table 3). According to Table 4, both education and physical activity made a significant unique contribution to the model. In fact, with one unit increase in PASE, the score of MMSE increases by 0.27 unit Table 4. Subjects were divided into low $(\mathrm{N}=39)$, moderate $(\mathrm{N}=42)$ and high $(\mathrm{N}=40)$ physical activity groups to compare cognitive impairment precisely. The results of ANCOVA indicated that there was a significant difference in dementia score between the three physical activity levels $(\mathrm{F}=6.648, \mathrm{p}<0.01)$ Table 5 . To clear which groups had a significant difference, the Bonferroni test was used. Figure 1 shows the difference in MMSE scores in different physical activity groups. There was a significant difference between low and high physical activity $(\mathrm{P}<0.001)$.

Table 3: Model Summary of Hierarchical Regression

\begin{tabular}{|c|c|c|c|c|c|c|c|c|}
\hline Model & $\mathrm{R}$ & $\mathrm{R} 2$ & Adjusted R2 & $\Delta \mathrm{R} 2$ & $\Delta \mathrm{F}$ & $\mathrm{df1}$ & $\mathrm{df2}$ & sig \\
\hline 1 & $.597^{\mathrm{a}}$ & .356 & .345 & .356 & 32.619 & 2 & 118 & .000 \\
\hline 2 & $.650^{\mathrm{b}}$ & .422 & .407 & .066 & 13.400 & 1 & 117 & .000 \\
\hline
\end{tabular}

apredictors (constant), age, education

${ }^{b}$ predictors (constant), age, education, physical activity

Dependent Variable: Dementia

Table 4: Summary of Hierarchical Regression analysis for variables predicting Dementia.

Dependent variable: Dementia.

\begin{tabular}{|c|c|c|c|c|c|}
\hline Model & B & Std. Error & Beta & T & p \\
\hline \multirow{2}{*}{ constant } & 18.282 & 3.817 & & -1.604 & .000 \\
\cline { 2 - 6 } Age & -.073 & .046 & -.117 & 6.710 & .111 \\
\cline { 2 - 6 } education & 2.514 & .375 & .489 & 3.661 & .000 \\
\cline { 2 - 6 } \\
Physical activity
\end{tabular}

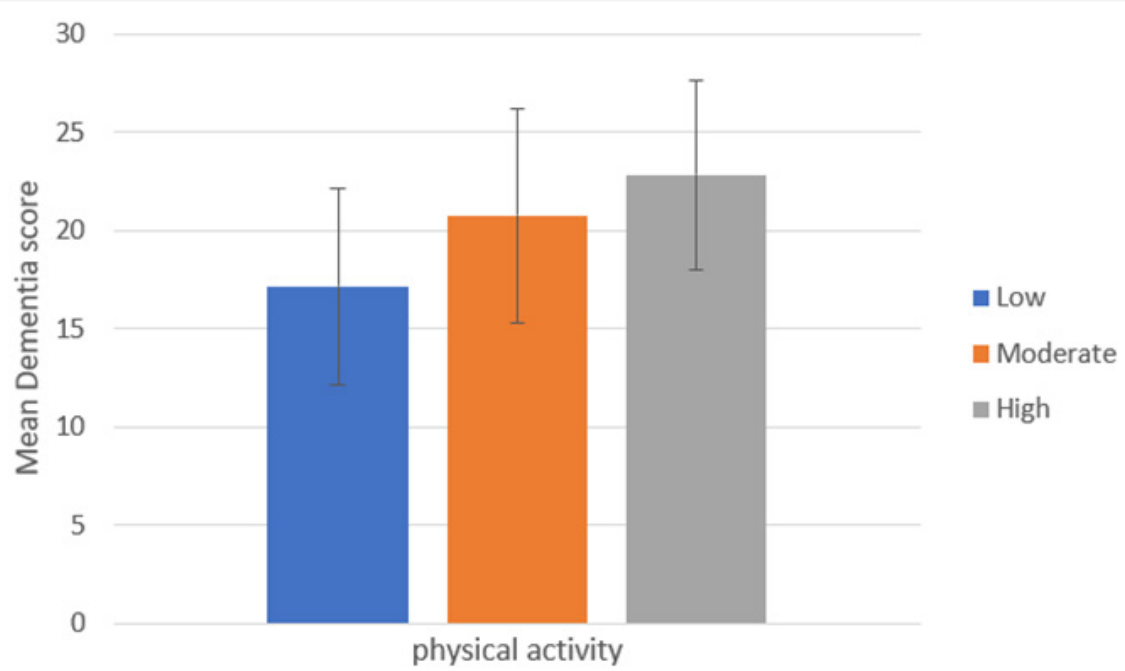

Figure 1: MMSE score in different physical activity levels. 
Table 5: ANCOVA results of MMSE scores regarding physical activity levels after controlling age and education variable.

\begin{tabular}{|c|c|c|c|c|c|}
\hline \multirow{2}{*}{ Groups } & Dementia & sum of squares & Mean square & F & \\
\cline { 2 - 3 } & Mean \pm SD & & & \\
Low activity & $17.15 \pm 5.040$ & & & \\
Moderate activity & $20.76 \pm 5.472$ & & & \\
High activity & $22.83 \pm 4.840$ & 248.755 & 124.378 & .002 \\
Total & $20.28 \pm 5.595$ & & & \\
\hline
\end{tabular}

\section{Discussion}

To the best of our knowledge, this is the first study to evaluate the level of physical activity and its relationship with cognitive function among elderly residents of nursing homes in Tehran. As mentioned in the literature, dementia is one of the most common geriatric syndromes, that no definitive treatment has been found for it, and its prevalence is much higher in nursing homes. As expected, our results showed that subjects with dementia had lower physical activity than non-dementia elderly. In particular, there was a negative relationship between age and dementia. Also, education and weight positively associated with the MMSE score. In addition, correlation analysis showed a significant positive relation between education and physical activity.

In this study, there was a negative and significant correlation between age and dementia in the elderly living in nursing homes. Also, the mean age was significantly higher in the dementia group. Our finding is consistent with the study of María M. Corrada et al. [29] showing the incidence of dementia continues to increase with age, with rates doubling every 5.5 years.

In this study, there was a significant positive correlation between physical activity level and dementia in the elderly living in nursing homes. In this aspect, if physical activity increase, the elderly's cognitive function increases. Also, the amount of activity undertaken by the dementia group was lower than non-dementia. The findings are supported by previous studies [30,31]. The role of exercise and physical activity in the prevention of dementia and its related mortality is well-understood. Evidence from animal and human studies suggest that aerobic exercise possibly can reduce age-related neurodegenerative and synaptic degradation processes, due to the direct effects on neurological diseases mechanisms or improvement of protective factors. Also, cerebrovascular diseases are the risk factors of dementia; but they can be controlled by aerobic exercise training [32]. Therefore, exercise and physical activity are considered as a prescription to reduce the risk factors for cognitive impairment. However, reports indicate that, despite the negative and destructive effects of inactivity, the levels of physical activity among elderly living in nursing homes are lower than other elderly people [33]. This might be due to a worse health condition. In fact, the most common barrier to physical activity is physical limitations. The difference in dementia score between low and high physical activity groups in our result suggests that elderly residents of nursing homes should involve in more physical activity, sports program and reduce time spent sedentary to prevent cognitive dysfunction.

In this study, there was a significant negative correlation between age and physical activity level of elderly living in nursing homes. Our finding is in line with the result of Speakman and Westerterp indicating that physical activity decreases with age in people aged over 52 years [34]. The amount of physical activity undertaken reflects individuals' physical fitness and physical capacity. As the age increases, the symptoms of geriatric syndromes, including weakness and fatigue, increase; which is along with decreased physical activity and physical function. The decline in physical fitness due to aging leads to impairment of daily activities and normal function of elderly people.

In this study, there was a significant and positive correlation between the level of education and dementia among the elderly living in nursing homes. Also, there was a significant difference between the level of education between dementia and nondementia groups. Moreover, the level of education had a significant contribution to predict dementia status. Our result is in agreement with the findings of former studies[35,36]. To explain this, researchers have proposed a cognitive reserve mechanism [35]. However, in many studies, Lower education was not associated with a greater risk of dementia. In fact, the relationship between the level of education and the risk of dementia is changed by the study population [37]. A meta-analysis by sharp et al in 2011 suggested that the effect of education on dementia risk should be evaluated through the lifespan. To explain more, the relationship between education and dementia will be more consistent, if the years of education reflect cognitive capacity. In fact, for some people, the education period may be linked to their deep interest to participate more in learning and cognitive activities; while for others, it is just a formal education [38].

In this study, there was a positive and significant correlation between educational level and physical activity in the elderly living in nursing homes. Probably peoples' awareness would increase the effects and benefits of physical activity toward prevention, control 
and treatment of various diseases by passing different educational levels, which encourage them to follow a healthier and more active lifestyle.In this study, there was a significant positive correlation between weight and dementia in the elderly living in nursing homes. Recent clinical guidelines on the prevention of dementia consider obesity as a modifiable factor, while there are relatively few and contradictory evidence. A study by Kivimäki et al. in 2018 reported that the relationship between BMI and dementia is actually related to two processes. One is associated with the body fat increase in middle-age that increases the risk of dementia; and the other is associated with weight loss during the aging and pre-dementia phase. For these reasons, people with dementia may have a higher BMI, many years before to be diagnosed, but by approaching to dementia phase, they have a lower BMI than healthy people [39]. This hypothesis is supported by the fact that bodyweight decreases with aging due to muscle mass reduction and metabolic changes [40].

There are some limitations to this study. First, many of the elderly people living in nursing homes suffering from physical or mental conditions who could not participate in the study so, the number of subjects was small. Also, this study was limited to the Tehran region; this fact reduces the generalizability of the results. Second, the cross-sectional design of the study cannot provide cause and effect.The results indicate that the physical activity of the elderly at nursing homes associates with the improvement of their cognitive function in many aspects such as short-term memory, attention, language, and etc. Moreover, it is essential to level up the public awareness of the elderly and their families about the benefits of physical activity and its effects on physical and mental health. Clearly, the role of an exercise physiologist to increase physical activity of elderly residents is tangible.

\section{Conclusion}

The findings indicate that a higher level of physical activity decreases the risk of dementia syndrome development. Consequently, it is essential to hold sports classes by exercise physiologists and also provide favorable conditions to encourage elderly residents of nursing homes to participate in them.

\section{Conflicts of Interest}

The authors declare that there is no conflict of interest with any financial organization regarding the material discussed in the manuscript.

\section{Authors Contributions}

Author A has given substantial contributions to the conception or the design of the manuscript, author $\mathrm{C}$ and author $\mathrm{D}$ to acquisition, analysis and interpretation of the data. All authors have participated to drafting the manuscript, author A revised it critically. All authors read and approved the final version of the manuscript.
All authors read and approved the final version of the manuscript

\section{Acknowledgment}

We would like to thank subjects participated in the study and members of nursing homes who assist us in this study.

\section{References}

1. (2018) Ageing and health. World Health Organization.

2. (2016) Population and Housing Censuses.

3. Jaul E, Barron J (2017) Age-Related Diseases and Clinical and Public Health Implications for the 85 Years Old and Over Population. Front Public Health 5: 335.

4. Qoronfleh M (2017) Response to the Burden and Impact of Dementia Through Policy and Innovation. International Journal of Nutrition Pharmacology Neurological Diseases 7(4): 73-75.

5. Sharifi F, Fakhrzadeh H, Varmaghani M, Masoud Arzaghi S, Alizadeh Khoei, et al. (2016) Prevalence of Dementia and Associated Factors among Older Adults in Iran: National Elderly Health Survey (NEHS). 19(12): 838-844

6. Takagi D, Nishida Y, Fujita D (2015) Age-associated changes in the level of physical activity in elderly adults. J Phys Ther Sci 27(12): 3685-3687.

7. Mac Nee W, Rabinovich RA, Choudhury G (2014) Ageing and the border between health and disease. European Respiratory Journal 44(5): 13321352

8. Cunningham EL, Mc Guinness B, Herron B, Passmore AP (2015) Dementia. Ulster Med J 84(2): 79-87.

9. Ates Bulut E, Soysal P, Isik AT (2018) Frequency and coincidence of geriatric syndromes according to age groups: single-center experience in Turkey between 2013 and 2017. Clin Interv Aging 13: 1899-1905.

10. (2018) The top 10 causes of death. World Health Organization.

11. Prince M AE, Guerchet M, Emiliano Albanese, Matthew Prina (2014) Dementia and risk reduction: an analysis of protective and modifiable factors. World Alzheimer Report 2014.

12. (2019) 10 facts on dementia. World Health Organization.

13. Mayeux R, Stern Y (2012) Epidemiology of Alzheimer disease. Cold Spring Harb Perspect Med 2(8): 10.

14. Kvæl LAH, Bergland A, Telenius EW (2017) Associations between physical function and depression in nursing home residents with mild and moderate dementia: a cross-sectional study. BMJ Open 7(7).

15. Sadeghi M, Kazemi HR (20014) Prevalence of Dementia and Depression among Residents of Elderly Nursing Homes in Tehran Province. J Iranian Journal of Psychiatry and Clinical Psychology 9(4): 49-55.

16. Abell JG, Kivimäki M, Dugravot A, Tabak AG, Fayosse A, et al. (2018) Association between systolic blood pressure and dementia in the Whitehall II cohort study: role of age, duration, and threshold used to define hypertension. Eur Heart J 39(33): 3119-3125.

17. Norton S, Matthews FE, Barnes DE, Yaffe K, Brayne C (2014) Potential for primary prevention of Alzheimer's disease: an analysis of populationbased data. The Lancet Neurology 13(8): 788-794.

18. Kushkestani M, Parvani M, Ebrahimpour S, Bathaeezadeh Y (2020) The relationship between drug use, sleep quality and quality of life in dormitory students at Allameh Tabataba'i University, Iran. Population Medicine 2 .

19. Tartibian B, Kushkestani M, Ebrahimpour S, Parvani M (2020) Relationship between the Level of Physical Activity and Nutritional Status with Fatigue in Elderly Residents of Rest Homes in Tehran 1: 155168. 
20. Kushkestani M, Parvani M, Ebrahimpour S, Seyed N, Bathaeezadeh Y (2019) The Relationship between Body Composition with Blood Pressure and Sleep Quality in Male Dormitory Student at Allameh Tabataba'i University. New Approaches in Sport Sciences 1: 77-92.

21. Tartibian B, Kushkestani M, Ebrahimpour S (2019) The Effect of 12-Week Endurance Training on Lipid Profiles and Fat Percentage of Overweight Girls. New Approaches in Sport Sciences 1(1): 189-200.

22. Kushkesthani M, Parvani M, Moradi K, Moghadassi M (2020) Malnutrition is Associated with Cognitive Function, Tiredness and Sleep Quality in Elderly Living Nursing Home. J Aging Sci 8: 233.

23. Gallaway PJ, Miyake H, Buchowski MS, Shimada M, Yoshitake Y, et al (2017) Physical Activity: A Viable Way to Reduce the Risks of Mild Cognitive Impairment, Alzheimer's Disease, and Vascular Dementia in Older Adults. Brain Sci 7(2): 22.

24. Tanigawa T, Takechi $H$, Arai $H$, Yamada M, Nishiguchi S, et al. (2014) Effect of physical activity on memory function in older adults with mild Alzheimer's disease and mild cognitive impairment. Epub 14(4): 758762.

25. Larson EB, Wang L, Bowen JD, Mc Cormick WC, Teri L, et al. (2006) Exercise Is Associated with Reduced Risk for Incident Dementia among Persons 65 Years of Age and Older Exercise, Aging, and Risk for Incident Dementia. Annals of Internal Medicine 144(2): 73-81.

26. Kolanowski A, Buettner L, Litaker M, Yu F (2006) Factors that relate to activity engagement in nursing home residents. Sage Journals 21(1): 1522.

27. Seyedian M, Falah M, Nouruzian M, Nejat S, Delavar A, et al. (2008) Validity of the Farsi version of Mini-Mental state Examination. journal of medical council of islamic republic of Iran 25(4): 408-414.

28. Ishaghi R, Mahmoudian SA, Asgarian R, sohrabi A (2011) Effect of Faithbased Education on Physical Activity on the Elderly J Iranian Journal of Medical Education 10(5): 1281-1288.

29. Corrada MM, Brookmeyer R, Paganini Hill A, Berlau D, Kawas CH (2010) Dementia incidence continues to increase with age in the oldest old: the 90+ study. Ann Neurol 67(1): 114-121.

30. Zhou Z, Fu J, Hong Y, Wang P, Fang Y (2017) Association between exercise and the risk of dementia: results from a nationwide longitudinal study in China. BMJ Open 7(12)

ISSN: $2574-1241$

DOI: 10.26717/BJSTR.2020.29.004800

Mehdi Kushkestani. Biomed J Sci \& Tech Res

This work is licensed under Creative

Commons Attribution 4.0 License

Submission Link: https://biomedres.us/submit-manuscript.php
31. Gagliardi C, Papa R, Postacchini D, Giuli C (2016) Association between cognitive status and physical activity: Study profile on baseline survey of my mind project. International journal of environmental research and public health 13(6): 585 .

32. Ahlskog JE, Geda YE, Graff Radford NR, Petersen RC (2011) Physical exercise as a preventive or disease-modifying treatment of dementia and brain aging. Mayo Clin Proc 86(9): 876-884.

33. Douma JG, Volkers KM, Engels G, Sonneveld MH, Goossens RHM, et al. (2017) Setting-related influences on physical inactivity of older adults in residential care settings: a review. BMC Geriatr 17(1): 97.

34. Speakman JR, Westerterp KR (2010) Associations between energy demands, physical activity, and body composition in adult humans between 18 and $96 \mathrm{y}$ of age. The American journal of clinical nutrition 92(4): 826-834.

35. Darwish H, Farran N, Assaad S, Chaaya M (2018) Cognitive reserve factors in a developing country: education and occupational attainment lower the risk of dementia in a sample of Lebanese older adults. Frontiers in aging neuroscience 10: 277 .

36. Lenehan ME, Summers MJ, Saunders NL, Summers JJ, Vickers JC (2015) Relationship between education and age-related cognitive decline: a review of recent research. Psychogeriatrics 15(2): 154-162.

37. Gross AL, Mungas DM, Crane PK, Gibbons LE, Mac Kay Brandt A, et al. (2015) Effects of education and race on cognitive decline: An integrative study of generalizability versus study-specific results. Psychol Aging 30(4): 863-880

38. Sharp ES, Gatz M (2011) Relationship between education and dementia: an updated systematic review. Alzheimer Dis Assoc Disord 25(4): 289304.

39. Kivimäki M, Luukkonen R, Batty GD, Ferrie JE, Pentti J, et al. (2018) Body mass index and risk of dementia: Analysis of individual level data from 1.3 million individuals. Alzheimers Dement 14(5): 601-609.

40. St Onge M P, Gallagher D (2010) Body composition changes with aging: The cause or the result of alterations in metabolic rate and macronutrient oxidation? Nutrition 26: 152-155.

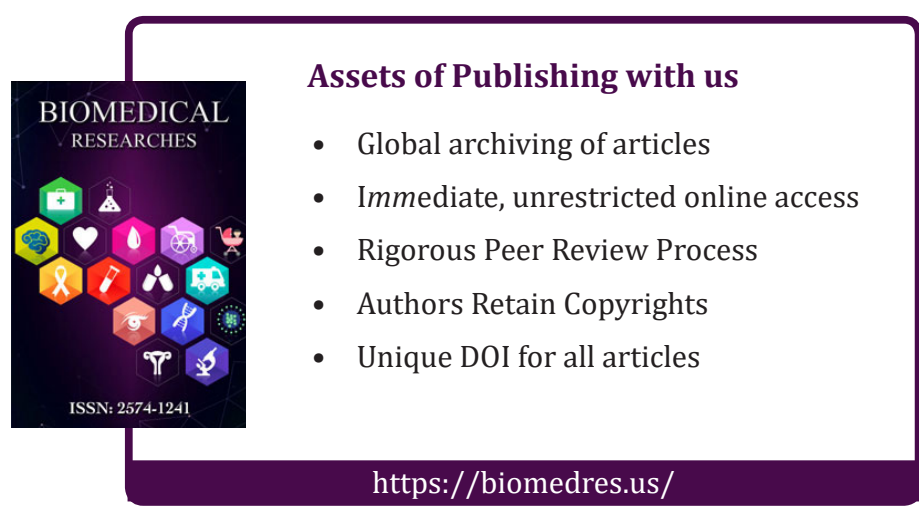

